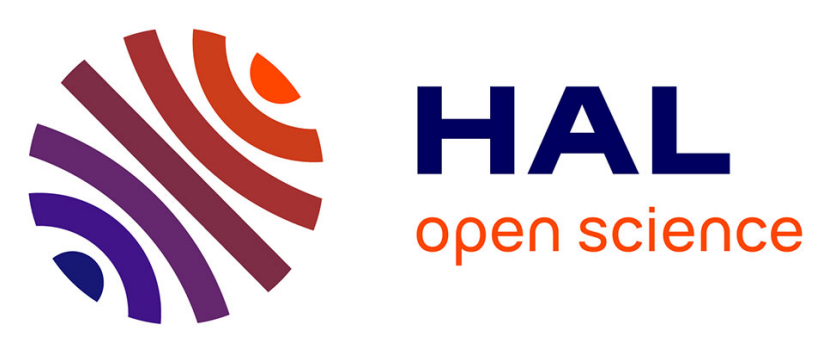

\title{
Organizational and psychosocial risk factors for carpal tunnel syndrome: a cross-sectional study of French workers
}

\author{
Pascal Rigouin, Catherine Ha, Julie Bodin, Audrey Petit, Alexis Descatha, \\ Marcel Goldberg, Yves Roquelaure
}

\section{To cite this version:}

Pascal Rigouin, Catherine Ha, Julie Bodin, Audrey Petit, Alexis Descatha, et al.. Organizational and psychosocial risk factors for carpal tunnel syndrome: a cross-sectional study of French workers. International Archives of Occupational and Environmental Health, 2014, 87, pp.147-54. 10.1007/s00420013-0846-0 . hal-03390151

\section{HAL Id: hal-03390151 \\ https://univ-angers.hal.science/hal-03390151}

Submitted on 21 Oct 2021

HAL is a multi-disciplinary open access archive for the deposit and dissemination of scientific research documents, whether they are published or not. The documents may come from teaching and research institutions in France or abroad, or from public or private research centers.
L'archive ouverte pluridisciplinaire HAL, est destinée au dépôt et à la diffusion de documents scientifiques de niveau recherche, publiés ou non, émanant des établissements d'enseignement et de recherche français ou étrangers, des laboratoires publics ou privés. 


\title{
Organizational and psychosocial risk factors for carpal tunnel syndrome: a cross-sectional study of French workers
}

\author{
Pascal Rigouin $\cdot$ Catherine Ha $\cdot$ Julie Bodin $\cdot$ \\ Audrey Petit Le Manac'h · Alexis Descatha • \\ Marcel Goldberg $\cdot$ Yves Roquelaure
}

Received: 23 April 2012/Accepted: 11 January 2013/Published online: 29 January 2013

(C) Springer-Verlag Berlin Heidelberg 2013

\begin{abstract}
Purpose The aim of the study was to examine the organizational and psychosocial risk factors for carpal tunnel syndrome (CTS) in workers exposed to various levels of work-related constraints, with a special focus on factors related to the work organization.

Methods From 3,710 workers, representative of a French region's working population, trained occupational physicians diagnosed a total of 156 cases of CTS between 2002 and 2005. Diagnoses were established by standardized physical examination, while personal factors and work exposure were assessed by self-administered questionnaires. Statistical associations between CTS and personal and work-related factors were analyzed for each gender using logistic regression modeling.

Results Among the factors related to work organization, working with temporary workers was associated with CTS for women $(\mathrm{OR}=1.99,95 \% \mathrm{CI} 1.23-3.25)$, but not for men. Task rotation during the job $(\mathrm{OR}=2.4595 \% \mathrm{CI}$
\end{abstract}

P. Rigouin · J. Bodin $(\bowtie) \cdot$ A. P. Le Manac'h · Y. Roquelaure Laboratoire d'ergonomie et d'épidémiologie en santé au travail (LEEST), LUNAM Université, Université d'Angers,

Angers, France

e-mail: julie.bodin@univ-angers.fr

C. Ha

Département santé travail, Institut de veille sanitaire

(DST-InVS), Saint-Maurice, France

\section{A. P. Le Manac'h · Y. Roquelaure \\ CHU Angers, Angers, France}

\author{
A. Descatha $\cdot$ M. Goldberg \\ Inserm, Centre de recherche en Epidémiologie et Santé \\ des Populations, Université de Versailles St-Quentin, \\ UMRS 1018, Villejuif, France
}

1.41-4.24) and work pace dependent on quantified targets $(\mathrm{OR}=1.9395 \%$ CI 1.08-3.46) were associated with CTS only for men. The work-related psychosocial factors highlighted by the logistic modeling were high psychological demand for women $(\mathrm{OR}=1.90,95 \% \quad \mathrm{CI}$ 1.17-3.09) and low skill discretion $(\mathrm{OR}=1.77,95 \% \mathrm{CI}$ 1.01-3.11) for men.

Conclusion This study has identified some psychosocial factors and factors related to work organization associated with clinically diagnosed and symptom-only cases of CTS as well as personal and biomechanical factors. However, due to the cross-sectional design of the study, no causal conclusion could be drawn and longitudinal studies are necessary to confirm these results.

Keywords Carpal tunnel syndrome $\cdot$ Risk factors · Work organization · Psychosocial factors · Personal factors ·

Physical exposure

\section{Introduction}

Carpal tunnel syndrome (CTS) is a major occupational health problem with high social and economic implications (Palmer and Hanrahan 1995; Atroshi et al. 1999; Roquelaure et al. 2008). Prevalence rates of CTS confirmed by electrodiagnostic testing vary between 2.7 and $5.8 \%$ in the general population (De Krom et al. 1992; Atroshi et al. 1999). Greater prevalence has been reported in the working population, reaching $10 \%$ or more in specific occupations, such as meat packing and construction industries (Hagberg et al. 1995; Roquelaure et al. 2001; Rosecrance et al. 2002).

Several personal factors have been reported to be associated with CTS, including female gender, age, overweight and obesity and comorbidity such as diabetes mellitus 
(Stevens et al. 1992; Becker et al. 2002). Epidemiological studies have demonstrated an increased risk of CTS in occupations involving repetitive movements, high levels of hand-arm vibration, forceful manual exertion, bending/ twisting of the wrist and their combination (Roquelaure et al. 1997; Armstrong et al. 2008; Maghsoudipour et al. 2008; Mattioli et al. 2009; Shiri et al. 2009; Burt et al. 2011; Bonfiglioli et al. 2012). Recent literature reviews have confirmed the association between CTS and these occupational risk factors (Palmer et al. 2007; van Rijn et al. 2009), but few have reported associations between psychosocial work exposure (low social support, high psychosocial demand and low decision latitude) and CTS (Bongers et al. 2002, 2006).

Factors related to work organization, such as "lean management," assembly line working or absence of job rotation, have rarely been studied (Roquelaure et al. 1997; Leclerc et al. 1998; Wang et al. 2007; Maghsoudipour et al. 2008). Recently, Roquelaure et al. reported that temporary workers suffered from UEMSDs of the wrist/hand region more often than permanent workers (Roquelaure et al. 2012). However, no literature review has mentioned factors related to work organization as risk factors for CTS or hand/wrist symptoms. We therefore focused in this study on the relationship between CTS and factors related to work organization.

The purpose of this study, using the data of the surveillance program for upper-extremity musculoskeletal disorders (UE-MSDs) in the working population of the French Loire Valley region, was to examine the organizational and psychosocial risk factors for CTS in workers exposed to various levels of work-related constraints, with a special focus on factors related to the work organization.

\section{Methods}

This cross-sectional study was conducted in the Loire Valley region of West-Central France on the basis of an epidemiological surveillance program. Data were collected through the participation of 83 occupational physicians (OP) who volunteered to take part in the study (18\% of OPs of the region), and were representative of the region's OPs. The economic structure of the region, which represents $5 \%$ of the French working population, is diversified and similar to that of most French regions (Ha et al. 2009). In France, at the time of this study, all salaried workers, including temporary and part-time workers, underwent a mandatory annual health examination by an OP in charge of the medical surveillance of a group of companies. All OPs were trained by the investigators to randomly include workers and to perform a standardized physical examination between April 2002 and April 2005. Subjects were selected at random, following a two-stage sampling procedure: first, 15-45 half-days of scheduled examinations for each OP were chosen for sampling by the investigators. Next, using random sampling tables, each OP included from the schedule 1 out of 10 workers on the half-days of worker examinations considered. A self-administered questionnaire including personal and work-related characteristics was filled out by workers just before the medical examination and checked by the OP at the beginning of the medical examination.

The population included in this study comprised 3,710 workers [2,161 men (58\%) and 1,549 women (42\%)] aged between 20 and 59 years [mean age 38.7 years, standard deviation (SD) 10.3 years] representing about $3.4 \%$ of the regional workforce. Comparison of the socioeconomic status with the French census of 1999 (http://www.insee.fr) showed no major differences for either gender (Roquelaure et al. 2006).

The presence of nonspecific wrist pain during the preceding 12 months and the preceding 7 days was identified using a Nordic style questionnaire (Hagberg et al. 1995; Roquelaure et al. 2006). In cases of wrist pain occurring during the preceding 12 months, a physical examination was performed by the OP using a standardized clinical procedure that strictly applied the methodology and clinical tests of the "European consensus criteria document" for CTS. Five other UE-MSDs were diagnosed in case of symptoms in the anatomy area concerned (i.e., rotator cuff syndrome, lateral epicondylitis, ulnar tunnel syndrome, De Quervain's disease and flexor-extensor peritendinitis or tenosynovitis of the forearm-wrist region) (Sluiter et al. 2001).

Two definitions of CTS were used

- Clinically diagnosed cases of CTS were defined (1) as subjects who had symptoms on the day of the examination or for at least 4 days during the preceding 7 days including intermittent paresthesias or pain in at least two of the first three digits (symptoms may also be present at night, causing pain in the palm, wrist or radiating proximal to the wrist) with (2) positive results for at least one of the following tests during the physical examination: flexion and compression test, carpal compression test, Phalen's test and Tinel's test.

- Symptom-only cases of CTS were defined by (1) the presence of symptoms without (2) positive test results during the physical examination.

Each OP received guidelines describing the clinical procedure (including diagnostic criteria charts and photographs of clinical tests) and underwent a 3-h training program to standardize physical examinations.

The personal and work-related factors were assessed using the self-administered questionnaire. The organizational 
constraints assessed were time constraints, production norms, job rotation, working with temporary workers (regardless of the worker's employment contract) and visual demand. The psychosocial constraints at work were assessed according to the Demand-Control-Support model, using the validated French version of the Job Content Questionnaire (Niedhammer 2002; Roquelaure et al. 2006).

In order to take into account the personal and biomechanical risk factors of CTS known in the literature (Hagberg et al. 1995; van Rijn et al. 2009), the multivariate models were adjusted for age, BMI, postures with extreme wrist bending, use of vibrating hand tools, manual force and repetitiveness in multivariate models.

The BMI was calculated and, like age, was considered as a continuous variable, after verification of the linearity of the logit. A prior history of at least one UE-MSD was not investigated because this variable shares common risk factors with CTS (chi-square test, $p<0.0001$ in both genders). The biomechanical factors were quantified according to an European consensus (Sluiter et al. 2001), except for manual force, which was approached using the Borg Scale for Rating of Perceived Exertion (20 RPE) graduated from 6 to 20 (maximum exertion) (Hagberg et al. 1995). Workers at risk were dichotomized at the third quartile ( $\geq 15$ for men and $\geq 14$ for women). Postures for different hand and wrist movements were illustrated with pictures in order to facilitate workers' understanding. Response categories were presented on a 4-level Likerttype scale as follows: never or practically never, rarely $(<2 \mathrm{~h} /$ day), often ( $-4 \mathrm{~h} /$ day) and always ( $\geq 4 \mathrm{~h} /$ day) and dichotomized to 2 or $4 \mathrm{~h}$. We combined "postures with extreme wrist bending" and "high perceived physical exertion" because of confounding problem between the two variables.

The outcome was defined by subject, and therefore, bilateral cases of CTS counted as one disorder, not two. The relationship between CTS and potential risk factors was studied by binary logistic regression modeling, and analyses were performed separately for men and women in order to reveal possible differences in work-related factors between genders (Hagberg et al. 1995; Roquelaure et al. 2006; Silverstein et al. 2009). A three-level process was followed until a final model was selected. In stage 1, univariate analyses were performed with each of the potential explanatory variables, and nonsignificant variables ( $p$ value $\geq 0.20$ ) were excluded from further analyses, except for age which was forced into all models. In stage 2, the independent variables not excluded in stage 1 were grouped and backward multivariate logistic regression models were then performed for each group of factors (organizational and psychosocial factors) with age forced into the model. Nonsignificant variables $(p$ value $\geq 0.10$ ) were excluded after this stage. In stage 3 , all remaining variables were included in a global multivariate logistic regression model until a final model was selected. From manual backward selection, only significant variables with a $p$ level of 0.05 were retained. A factor was considered to be a confounder when its removal changed the estimate of the beta coefficients for at least one parameter by more than $15 \%$. Such a factor was forced into the final model or combined with other variables using dichotomous cut off points. All covariates deleted during the selection processes were put back into the final model in order to identify new covariates associated with the presence of CTS $(p<0.05)$ or confounding factors.

Several interactions were assessed in the final model. Only interaction terms contributing to the final model with a $p$ value of $<0.05$ were retained in the model.

We chose to focus the study on factors related to the work organization and psychosocial factors, which have rarely been mentioned as risk factors for CTS.

The Hosmer and Lemeshow test was used to determine goodness of fit of the logistic model. All analyses were performed with SAS statistical software packages, version 9.2 (SAS Institute Inc, Cary, NC, USA).

Finally, the final model was performed only in workers with clinically diagnosed CTS.

\section{Results}

One hundred and fifty-six cases (89 women and 67 men) of CTS were diagnosed, including 113 clinically diagnosed cases (62 women and 51 men) and 43 symptom-only cases. No major differences were found between these groups in terms of personal factors (gender, age, BMI) or current occupational category. CTS was bilateral in 65 cases $(41.7 \%)$, and no major differences were found between unilateral and bilateral CTS in terms of personal factors and current occupational category. The levels of prevalence of CTS in the male and female working populations were $3.1 \%$ (95\% CI $2.4-3.8)$ and $5.7 \%(95 \%$ CI 4.6-6.9), respectively. The logistic models of CTS differed between genders and highlighted several psychosocial factors and factors related to the work organization (Table 1), after adjustment on personal and biomechanical factors. Adjustments were performed on age, BMI, too little recovery time $(<10 \mathrm{~min}$ break possible per hour) when highly repetitive movements are performed, postures with extreme wrist bending ( $\geq 2 \mathrm{~h} /$ day) associated with high perceived physical exertion and use of vibrating hand tools ( $\geq 2 \mathrm{~h} /$ day).

Among the factors related to work organization, working with temporary workers was associated with CTS for women $(\mathrm{OR}=1.99,95 \%$ CI 1.23-3.25), but not for men. The women working with temporary workers were mainly 
Table 1 Multivariate models for CTS among men and women

\begin{tabular}{|c|c|c|c|c|c|c|c|c|c|c|}
\hline & \multicolumn{5}{|c|}{ Men $\left(n=1,942, n_{\text {CTS }}=59\right)$} & \multicolumn{5}{|c|}{ Women $\left(n=1,456, n_{\mathrm{CTS}}=82\right)$} \\
\hline & $n_{\text {sample }}$ & $n_{\text {CTS }}$ & OR & $95 \%$ IC & $p$ value & $n_{\text {sample }}$ & $n_{\mathrm{CTS}}$ & OR & $95 \%$ IC & $p$ value \\
\hline \multicolumn{11}{|l|}{ Personal factors } \\
\hline Age (1-year increment) & & & 1.05 & $1.02-1.08$ & 0.001 & & & 1.07 & $1.04-1.10$ & $<0.001$ \\
\hline Body mass index ( $1 \mathrm{~kg} / \mathrm{m}^{2}$ increment $)$ & & & 1.10 & $1.02-1.17$ & 0.009 & & & 1.04 & $0.99-1.09$ & 0.108 \\
\hline \multicolumn{11}{|l|}{ Occupational factors } \\
\hline \multicolumn{11}{|l|}{ Factors related to the work organization } \\
\hline Work pace dependent on quantified target & & & & & 0.026 & & & & & \\
\hline No & 888 & 18 & 1 & & & & & & & \\
\hline Yes & 1,054 & 41 & 1.93 & $1.08-3.46$ & & & & & & \\
\hline Job/task rotation ( $\geq 1$ job rotation per week) & & & & & 0.001 & & & & & \\
\hline No & 1,174 & 23 & 1 & & & & & & & \\
\hline Yes & 768 & 36 & 2.45 & $1.41-4.24$ & & & & & & \\
\hline Work with temporary workers & & & & & & & & & & 0.005 \\
\hline No & & & & & & 1,012 & 43 & 1 & & \\
\hline Yes & & & & & & 444 & 39 & 1.99 & $1.23-3.25$ & \\
\hline $\begin{array}{l}\text { Too little recovery time }(<10 \text { min break possible } \\
\text { per hour) when highly repetitive movements are } \\
\text { performed }\end{array}$ & & & & & 0.134 & & & & & 0.114 \\
\hline No & 1,855 & 53 & 1 & & & 1,350 & 68 & 1 & & \\
\hline Yes & 87 & 6 & 2.02 & $0.81-5.07$ & & 106 & 14 & 1.73 & $0.88-3.42$ & \\
\hline \multicolumn{11}{|l|}{ Working postures and biomechanical constraints } \\
\hline $\begin{array}{l}\text { Extreme wrist bending posture ( } \geq 2 \mathrm{~h} / \text { day) and high } \\
\text { physical demand }^{\text {a }}\end{array}$ & & & & & 0.103 & & & & & 0.162 \\
\hline No factor & 1,056 & 20 & 1 & & & 840 & 32 & 1 & & \\
\hline One factor & 626 & 24 & 1.64 & $0.87-3.10$ & & 442 & 33 & 1.64 & $0.97-2.78$ & \\
\hline Both factors & 260 & 15 & 2.21 & $1.04-4.68$ & & 174 & 17 & 1.57 & $0.79-3.12$ & \\
\hline Use of vibrating hand tools ( $\geq 2 \mathrm{~h} /$ day) & & & & & 0.192 & & & & & 0.026 \\
\hline No & 1,578 & 42 & 1 & & & 1,395 & 72 & 1 & & \\
\hline Yes & 364 & 17 & 1.52 & $0.81-2.85$ & & 61 & 10 & 2.44 & $1.11-5.38$ & \\
\hline \multicolumn{11}{|l|}{ Psychosocial factors at work } \\
\hline Low skill discretion & & & & & 0.047 & & & & & \\
\hline No & 970 & 21 & 1 & & & & & & & \\
\hline Yes & 972 & 38 & 1.77 & $1.01-3.11$ & & & & & & \\
\hline High psychological demand & & & & & & & & & & 0.009 \\
\hline No & & & & & & 728 & 28 & 1 & & \\
\hline Yes & & & & & & 728 & 54 & 1.90 & $1.17-3.09$ & \\
\hline
\end{tabular}

Subjects with no missing value for the risk factors in the multivariate model; number of subjects excluded from analyses because of missing values: 219 men and 93 women; Hosmer-Lemeshow goodness-of-fit test: $p$ value $=0.762$ for the model for men and $p$ value $=0.953$ for the model for women

Bold values indicate $p<0.05$

${ }^{a}$ RPE Borg scale $\geq 15$ for men and $\geq 14$ for women

industrial (unskilled or skilled) blue collar workers. On the other hand, task rotation during the job $(\mathrm{OR}=2.4595 \%$ CI 1.41-4.24) and work pace dependent on quantified target $(\mathrm{OR}=1.9395 \% \mathrm{CI} 1.08-3.46)$ were associated with CTS only for men.

The work-related psychosocial factors highlighted by the logistic modeling were high psychological demand for women $(\mathrm{OR}=1.90,95 \% \mathrm{CI} 1.17-3.09)$ and low skill discretion $(\mathrm{OR}=1.77,95 \%$ CI 1.01-3.11) for men. Tests for interactions in the final model showed no modified effect.

In analyses with only clinically diagnosed CTS as dependent variable (excluding symptom-only cases), task rotation during the job $(\mathrm{OR}=2.88,95 \%$ CI 1.52-5.46) and low skill discretion (OR $=2.12,95 \%$ CI 1.09-4.13) remained associated with CTS with a $p$ level of 0.05 in 
male workers, whereas work pace dependent on quantified target was not significant $(\mathrm{OR}=1.61,95 \%$ CI 0.84-3.09, $p=0.151$ ). For women, working with temporary workers $(\mathrm{OR}=2.27,95 \%$ CI 1.28-4.04) was associated with CTS, whereas high psychosocial demand was of borderline of significance $(\mathrm{OR}=1.76,95 \%$ CI 0.99-3.12, $p=0.053)$.

\section{Discussion}

This study undertaken in a large representative sample of salaried workers showed that several factors related to work organization and psychosocial constraints were associated with CTS, after adjustment for the main personal and biomechanical factors. Our study confirms the relative importance of personal risk factors such as aging and high BMI (Werner et al. 2005; Armstrong et al. 2008; Silverstein et al. 2009) and of biomechanical risk factors for CTS (Palmer et al. 2007; van Rijn et al. 2009).

The study highlights associations between CTS and some factors related to work organization such as work pace dependent on quantified targets and job rotation for men and working with temporary workers for women. The factors related to work organization differed between genders after adjustment on personal and biomechanical factors, and this might reflect not only psychophysiological factors but also differences in exposure to constraints at work related to the gender division of work (Silverstein et al. 2009). The associations between CTS and work organization and psychosocial factors were generally lower than those between CTS and personal and biomechanical factors, as previously observed by Burt et al. in a group of health care and manufacturing workers (Burt et al. 2011).

Work pace dependent on quantified targets was associated with CTS in male workers (and to a lesser extent in women) after adjustment for the repetitiveness of the task and other potential confounders. Such paced work characterized the work organization in the manufacturing and meat processing industries involving assembly line workers performing highly repetitive jobs that are known to increase the risk of CTS (van Rijn et al. 2009; Dempsey et al. 2010).

Contrary to our expectations, job rotation between several workstations on various days of the week ( $\geq 1 /$ week) was highly associated with CTS among men after adjustments for personal and biomechanical factors. The literature on job rotation and hand-wrist MSDs is sparse and conflicting (Kuijer et al. 2005; Mathiassen 2006). Some studies have reported frequency of job rotation as a risk factor for symptoms in the hand/wrist region, while others using a case-control design in the manufacturing industry have shown an association between surgical cases of CTS and lack of job rotation among industrial workers, after adjustment for potential confounders (Roquelaure et al.
1997). Maghsoudipour et al. reported a trend to a protective effect of job rotation on CTS in automotive workers, since the relationship did not reach statistical significance after adjustment for potential confounders (Maghsoudipour et al. 2008). Job rotation may have several effects on the musculoskeletal constraints of the hand/wrist region, explaining the discrepancies of the literature (Mathiassen 2006). The concept is that job rotation of workers exposed to highly repetitive work with short cycles (such as assembly line workers or meat processing operators) aims to extend the task to be performed by working on several workstations. Such organization is expected to increase the variability of hand movements and consequently to decrease the mechanical load on the hand/wrist region by varying the biomechanical stresses and broadening the area of application of the mechanical load (Hagberg et al. 1995; Kuijer et al. 2005; Wells et al. 2010). In ergonomic practice, job rotation is often associated with increasing in the number of actions to be performed repetitively during the time cycle (job enlargement). These are the main biomechanical arguments in favor of job rotation as an organizational measure to prevent MSDs during repetitive work (Hagberg et al. 1995; Wells et al. 2010). However, job rotation can also have adverse effects. In a study involving refuse collectors, Kuijer et al. observed that job rotation may reduce the need for recovery and thus increase the risk of cumulative trauma of soft tissue (Kuijer et al. 2005). In our study, univariate analyses showed that job rotation was associated with biomechanical factors for both genders: workers exposed to job rotation were more exposed than nonexposed workers to biomechanical factors. Job rotation increases the complexity of the task and the number of actions to learn. This requires longer training periods to acquire sufficient knowledge of the tasks and to develop efficient skills. In the absence of adequate training periods, workers can be insufficiently skilled to cope with all dimensions of the tasks, leading them to adopt unsafe working techniques that may increase the risk of MSDs. Job rotation without adequate training may therefore be less effective than expected (Frazer et al. 2003). No information was collected in our study on the existence or absence of training periods before job rotation. Moreover, work experience more easily permits job rotation, and experienced workers were often deemed to be aging workers, who are more affected by CTS. We cannot exclude the possibility that some workers suffering from CTS before the cross-sectional study may have been allocated to enlarged jobs following wrist symptoms.

Working with temporary workers was highlighted in women by the final logistic model and by univariate analyses in men as a factor associated with CTS. This has never, to our knowledge, been reported in the literature. Working with temporary workers mostly involved women 
in permanent employment and not workers in temporary employment. It could be hypothesized that the work load of such experienced women was increased because they may have had to spend part of their working time training their less qualified temporary colleagues.

Several studies have failed to report any statistically significant association between CTS and psychosocial factors (Roquelaure et al. 2001; van Rijn et al. 2009), and no single dimension of the demand-control-support model of stress at work seemed to be more important for CTS than others (Bongers et al. 2006). In our study, some dimensions of the "demand-control-support" model of stress at work were associated with CTS in our study, that is, low skill discretion among men and high levels of psychological demand among women.

The study population was taken from a wide variety of activity sectors and occupations, representing a broad range of both physical and mental occupational tasks. Its high representativeness of the regional workforce allows greater generalization of the results than epidemiological studies conducted in selected occupations. Outcomes were clinically assessed by trained OPs using a rigorous physical examination, including standardized provocation tests, providing more accurate diagnosis of CTS than a questionnaire (Roquelaure et al. 2006; Sluiter et al. 2001).

The main personal and work-related potential risk factors for CTS described in the literature were taken into account. Because of the scarcity of information on the relationship between CTS and work organization (Leclerc et al. 1998), the logistic models of CTS were adjusted for the main personal and biomechanical factors in order to identify any potential relationship between CTS and psychosocial factors and factors related to work organization. More sophisticated multilevel statistical analyses would have been more appropriate to take into account the relationship between more general risk factors related to the work organization in a given company, such as paced work on assembly lines, and more specific biomechanical risk factors, such as repetitive pinching movements. It can be hypothesized that the former are closer in the theoretical chain of causality of risk factors for CTS.

One limitation of this study was the small number of clinically diagnosed CTS. However, the inclusion of symptom-only cases of CTS in addition to clinically diagnosed cases increased the statistical power of the study, and we have observed that significant factors were almost the same in both analyses. Moreover, due to the crosssectional design of the study, no causal conclusion could be drawn. We cannot exclude the possibility of inadvertent influence of potential expectations based on information in the questionnaire on the working conditions. Finally, the case definition used was based on symptoms and any physical examination maneuvers with no nerve conduction study. However, a recent review by Palmer et al. concluded that in population-based etiological research, simple case definitions of distal upper limb musculoskeletal disorders should normally suffice (Palmer et al. 2012). Furthermore, the comparison of different case definition of CTS in a large US cohort, including the one we used in the present study (Sluiter et al. 2001) and definition including nerve conduction study (Rempel et al. 1998), shows a fairly good agreement between different case definitions. This suggests that the results can be compared across different research studies of risk factors for CTS (Descatha et al. 2011).

In conclusion, the cross-sectional study has identified some psychosocial factors and factors related to work organization associated with clinically diagnosed and symptom-only cases of CTS as well as personal and biomechanical factors. These findings should be confirmed by more appropriate model for an association between work organization and CTS, for example, hierarchical modeling with a longitudinal design.

Acknowledgments This project was supported by grants from the French Institute for Public Health Surveillance, Saint-Maurice, France (Grant 9/25/2002-5 "Réseau expérimental de surveillance des troubles musculo-squelettiques") and the French National Research Agency (ANR-grant SEST-06-36). We thank the occupational physicians involved in the sentinel network: Doctors Abonnat, Adam, Addou, Agullo, Ansaloni, Aubrun, Banon, Bardet, Barraya, Beaurepaire, Becquemie, Berthelot, Bertin, Bertrand, Bidron, Biton, Biziou-Fouere, Bizouarne, Boisse, Bonamy, Bonneau, Bouchet, Bouguer, BourrutLacouture, Bourven, Bradane, Breton, Bricaud, Caillon, Camer, Cesbron, Chabot, Charlon, Chevalier, Chisacof, Chotard, Clement dit Pontieu, Compain, Coquin-Georgeac, Cordes, Cormier, Couet, Coutand, Da Costa, Dachert, Dadourian, Danielou, Darcy, Davenas, De Lansalut, De Lescure, Diquelou, Dopsent, Dubois, Dufrenne-Benetti, Dupas, Durand, Durand-Perdriel, Evano, Fache, Faline, Fontaine, Fosse, Frampas-Chotard, François, Garrabe, Gasseau, Giffard, Girard, Girardin, Guerin, Guessard, Guillaumin, Guillier, Guillimin, Guinel, Harinte, Harrigan, Hefti, Herrouet, Herson, Hervio, Hirigoyen, Houssin, Husquin, Jahan, Jarry, Jube, Kalfon, Kergresse, Khouri, Krai, Labraga, Laine, Laine-Colin, Lamotte, Lasnier, Laventure, Le Clerc, Le Dizet, Le Mauff, Lechevalier, Lecompte, Ledenvic, Leroux, Leroy-Maguer, Levrard, Levy, Ligeard, Logeay, Louineau, Lourtis, Lucas, Maeker, Maison, Mallet, Marquiset, Martin, Martin-Laurent, Mazoyer, Meritet, Meyer, Michel MC, Michel R, Migne-Cousseau, Moisan, Morvan, Mouchet, Moui, Nivet, Page, Parrot, Patillot, Perou, Pierfitte, Pinaud, Pineau, Pizzalla, Plessis, Plouhinec, Pocreaux, Prod'homme, Puichaud, Quince, Rabjeau, Raffray, Riberot, Riou, Robin, Robin-Riom, Roesch, Rouault, Roussel, Roux, Russu, Saboureault, Schlindwein, Soulard, Souvre-Debray, Spiesser, Thomas, Thomasset, Thomson, Tillette, Treillard, Tripodi, Verrier, Voisin.

Conflict of interest The authors declare that they have no conflict of interest.

\section{References}

Armstrong T, Dale AM, Franzblau A, Evanoff BA (2008) Risk factors for carpal tunnel syndrome and median neuropathy in a working population. J Occup Environ Med 50:1355-1364 
Atroshi I, Gummesson C, Johnsson R, Ornstein E, Ranstam J, Rosén I (1999) Prevalence of carpal tunnel syndrome in a general population. JAMA 282:153-158

Becker J, Nora DB, Gomes I, Stringari FF, Seitensus R, Panosso JS, Ehlers JC (2002) An evaluation of gender, obesity, age and diabetes mellitus as risk factors for carpal tunnel syndrome. Clin Neurophysiol 113:1429-1434

Bonfiglioli R, Mattioli S, Armstrong T, Graziosi F, Marinelli F, Farioli A, Violante F (2012) Validation of the ACGIH TLV for hand activity level in the OCTOPUS cohort: a two-year longitudinal study of carpal tunnel syndrome. Scand J Work Environ Health [Epub ahead of print]

Bongers PM, Kremer AM, ter Laak J (2002) Are psychosocial factors, risk factors for symptoms and signs of the shoulder, elbow, or hand/wrist? A review of the epidemiological literature. Am J Ind Med 41:315-342

Bongers PM, Ijmker S, van den Heuvel S, Blatter BM (2006) Epidemiology of work related neck and upper limb problems: psychosocial and personal risk factors (part I) and effective interventions from a bio behavioural perspective (part II). J Occup Rehabil 16:279-302

Burt S, Crombie K, Jin Y, Wurzelbacher S, Ramsey J, Deddens J (2011) Workplace and individual risk factors for carpal tunnel syndrome. Occup Environ Med 68:928-933

De Krom MC, Knipschild PG, Kester A, Thijs C, Boekkooi P, Spaans F (1992) Carpal tunnel syndrome: prevalence in the general population. J Clin Epidemiol 45:373-376

Dempsey PG, Mathiassen SE, Jackson JA, O'Brien NV (2010) Influence of three principles of pacing on the temporal organisation of work during cyclic assembly and disassembly tasks. Ergonomics 53:1347-1358

Descatha A, Dale A-M, Franzblau A, Coomes J, Evanoff B (2011) Comparison of research case definitions for carpal tunnel syndrome. Scand J Work Environ Health 37:298-306

Frazer MB, Norman RW, Wells RP, Neumann PW (2003) The effects of job rotation on the risk of reporting low back pain. Ergonomics 46:904-919

Ha C, Roquelaure Y, Leclerc A, Touranchet A, Goldberg M, Imbernon E (2009) The French Musculoskeletal Disorders surveillance program: pays de la Loire network. Occup Environ Med 66:471-479

Hagberg M, Silverstein B, Wells R, Smith M, Hendrick H, Carayon P, Pérusse M (1995) Work related musculoskeletal disorders (WMSDs): a reference book for prevention. Taylor \& Francis, London

Kuijer P, van der Beek A, van Dieën J, Visser B, Frings-Dresen M (2005) Effect of job rotation on need for recovery, musculoskeletal complaints, and sick leave due to musculoskeletal complaints: a prospective study among refuse collectors. Am J Ind Med 47:394-402

Leclerc A, Franchi P, Cristofari MF, Delemotte B, Mereau P, Teyssier-Cotte C, Touranchet A (1998) Carpal tunnel syndrome and work organisation in repetitive work: a cross sectional study in France. Study group on repetitive work. Occup Environ Med 55:180-187

Maghsoudipour M, Moghimi S, Dehghaan F, Rahimpanah A (2008) Association of occupational and non-occupational risk factors with the prevalence of work related carpal tunnel syndrome. J Occup Rehabil 18:152-156

Mathiassen SE (2006) Diversity and variation in biomechanical exposure: what is it, and why would we like to know? Appl Ergon 37:419-427

Mattioli S, Baldasseroni A, Bovenzi M, Curti S, Cooke RMT, Campo G, Barbieri PG, Ghersi R, Broccoli M, Cancellieri MP, Colao AM, Dell'omo M, Fateh-Moghadam P, Franceschini F, Fucksia S, Galli P, Gobba F, Lucchini R, Mandes A, Marras T, Sgarrella
C, Borghesi S, Fierro M, Zanardi F, Mancini G, Violante FS (2009) Risk factors for operated carpal tunnel syndrome: a multicenter population-based case-control study. BMC Public Health 9:343

Niedhammer I (2002) Psychometric properties of the French version of the Karasek Job Content Questionnaire: a study of the scales of decision latitude, psychological demands, social support, and physical demands in the GAZEL cohort. Int Arch Occup Environ Health 75:129-144

Palmer DH, Hanrahan LP (1995) Social and economic costs of carpal tunnel surgery. Instr Course Lect 44:167-172

Palmer KT, Harris EC, Coggon D (2007) Carpal tunnel syndrome and its relation to occupation: a systematic literature review. Occup Med (Lond) 57:57-66

Palmer KT, Harris EC, Linaker C, Cooper C, Coggon D (2012) Optimising case definitions of upper limb disorder for aetiological research and prevention: a review. Occup Environ Med 69:71-78

Rempel D, Evanoff B, Amadio PC, de Krom M, Franklin G, Franzblau A, Gray R, Gerr F, Hagberg M, Hales T, Katz JN, Pransky G (1998) Consensus criteria for the classification of carpal tunnel syndrome in epidemiologic studies. Am J Public Health 88:1447-1451

Roquelaure Y, Mechali S, Dano C, Fanello S, Benetti F, Bureau D, Mariel J, Martin YH, Derriennic F, Penneau-Fontbonne D (1997) Occupational and personal risk factors for carpal tunnel syndrome in industrial workers. Scand J Work Environ Health 23:364-369

Roquelaure Y, Mariel J, Dano C, Fanello S, Penneau-Fontbonne D (2001) Prevalence, incidence and risk factors of carpal tunnel syndrome in a large footwear factory. Int J Occup Med Environ Health 14:357-367

Roquelaure Y, Ha C, Leclerc A, Touranchet A, Sauteron M, Melchior M, Imbernon E, Goldberg M (2006) Epidemiologic surveillance of upper-extremity musculoskeletal disorders in the working population. Arthritis Rheum 55:765-778

Roquelaure Y, Ha C, Pelier-Cady M, Nicolas G, Descatha A, Leclerc A, Raimbeau G, Goldberg M, Imbernon E (2008) Work increases the incidence of carpal tunnel syndrome in the general population. Muscle Nerve 37:477-482

Roquelaure Y, Petit LeManach A, Ha C, Poisnel C, Bodin J, Descatha A, Imbernon E (2012) Working in temporary employment and exposure to musculoskeletal constraints. Occup Med (Lond) 62(7):514-518

Rosecrance JC, Cook TM, Anton DC, Merlino LA (2002) Carpal tunnel syndrome among apprentice construction workers. Am J Ind Med 42:107-116

Shiri R, Miranda H, Heliövaara M, Viikari-Juntura E (2009) Physical work load factors and carpal tunnel syndrome: a populationbased study. Occup Environ Med 66:368-373

Silverstein B, Fan ZJ, Smith CK, Bao S, Howard N, Spielholz P, Bonauto D, Viikari-Juntura E (2009) Gender adjustment or stratification in discerning upper extremity musculoskeletal disorder risk? Scand J Work Environ Health 35:113-126

Sluiter JK, Rest KM, Frings-Dresen MH (2001) Criteria document for evaluating the work-relatedness of upper-extremity musculoskeletal disorders. Scand J Work Environ Health 27(Suppl 1):1-102

Stevens J, Beard C, O'Fallon W, Kurland L (1992) Conditions associated with carpal tunnel syndrome. Mayo Clinc Proc Mayo Clin 67:541

van Rijn RM, Huisstede BMA, Koes BW, Burdorf A (2009) Associations between work-related factors and the carpal tunnel syndrome-a systematic review. Scand J Work Environ Health 35:19-36

Wang P, Rempel DM, Harrison RJ, Chan J (2007) Work-organisational and personal factors associated with upper body 
musculoskeletal disorders among sewing machine operators. Occup Environ Med 64:806-813

Wells R, McFall K, Dickerson CR (2010) Task selection for increased mechanical exposure variation: relevance to job rotation. Ergonomics 53:314-323
Werner RA, Franzblau A, Gell N, Ulin SS, Armstrong TJ (2005) A longitudinal study of industrial and clerical workers: predictors of upper extremity tendonitis. J Occup Rehabil 15:37-46 